Avalaible online: https://ejournal.iai-tribakti.ac.id/index.php/pgmi

Article doi: https://doi.org/10.33367/jiee.v1i2.1300

\title{
Sertifikasi dan Upaya Meningkatkan Profesionalitas Guru di MI Misriu Al Hasan Kecamatan Mojo Kabupaten Kediri
}

\author{
${ }^{1}$ Ammar Kukuh Wicaksono, ${ }^{2 S S y a f i k ~ U b a i d i l a ~}$ \\ 1Institut Agama Islam Tribakti Kediri, 2Institut Agama Islam Tribakti Kediri, \\ 1ammar.kukuh@gmail.com,2Syafikubaidilla79@gmail.com
}

\begin{abstract}
Professional teachers are teachers who are competent in their fields. With certification, teacher competence will be further improved in order to better quality education. To be able to take part in the certification program, of course there are several conditions that must be fulfilled by certification participants. Fulfilling the requirements will make it easier to get an educator certificate. After obtaining a certificate, teacher educators must continue to strive to improve performance and professionalism as a form of responsibility as a professional teacher. This research is a qualitative research. Words and actions obtained from interviews are the main data sources in this study, while additional data is in the form of documents. The results of this study are, 1 . The terms and patterns that are passed by the teachers at MI Misriu Al Hasan are in accordance with the applicable regulations, there are three patterns that are followed, namely Portfolio, PLPG and PPG, 2. Efforts that have been made by certification teachers in MI Misriu Al Hasan Kraton Mojo Kediri in improving professionalism, including by increasing discipline, using appropriate and effective teaching methods, preparing themselves and materials that have been planned before carrying out learning, providing problem solving to students with problems intensively and participating in activities of professional organizations such as PGIN and KKG and NU community organizations. Other supporting activities include training and seminars.
\end{abstract}

Keywords : Teacher Certification, Efforts to Improve Professionalism.

\begin{abstract}
Abstrak
Guru yang professional adalah guru yang berkompeten dibidangnya. Dengan sertifikasi, kompetensi guru akan lebih ditingkatkan lagi guna kualitas Pendidikan yang lebih baik. Untuk dapat mengikuti program sertifikasi tentu ada beberapa ketentuan yang harus dipenuhi oleh para peserta sertifikasi. Pemenuhan persyaratan akan mempermudah dalam mendapatkan sertifikat pendidik. Setelah mendapat sertifikat pendidik guru harus terus berupaya meingkatkan kinerja dan profesionalitas sebagai bentuk tanggung jawab sebagai seorang guru professional. Penelitian ini merupakan penelitian kualitatif. Kata-kata dan tindakan yang diperoleh dari wawancara merupakan sumber data utama dalam penelitian ini, sedangkan data tambahan berupa dokumen-dokumen. Hasil penelitian ini yaitu, 1. Syarat dan pola yang dilalui oleh guru-guru di MI Misriu Al Hasan telah sesuai dengan ketentuan yang berlaku, ada tiga pola yang diikuti yaitu Portofolio, PLPG dan PPG, 2. Upaya yang telah dilakukan oleh guru


sertifikasi di MI Misriu Al Hasan Kraton Mojo Kediri dalam meningkatkan profesionalitas diantaranya dengan meningkatkan kedisiplinan, mengunakan metode mengajar yang sesuai dan efektif, mempersiapkan diri dan materi yang telah direncanakan sebelum melaksanakan pembelajaran, memberikan problem solving pada siswa bermasalah dengan intensif serta mengikuti kegiatan organisasi profesi seperti PGIN dan KKG serta organisasi kemasyarakatan NU. Kegiatan penunjang lain berupa diklat dan seminar.

Kata Kunci : Guru, Sertifikasi, Profesionalitas.

\section{Pendahuluan}

Berbicara soal problematika pendidikan secara umum di Indonesia, perlu melihat kualitas tingkat sumber daya manusianya (SDM) di Indonesia. Posisi Indonesia masih dibawah negara-negara lain di kawasan Asia Tenggara dan menempati urutan ke 53 negara-negara di dunia dalam hal kualitas SDM. Ada empat pilar yang digunakan World Economic Forum (WEF) untuk mengukur tingkat SDM tiap negara, salah satunya adalah tingkat pendidikan disamping kesehatan, pekerjaan, dan lingkungan. ${ }^{1}$ Oleh sebab itu, pendidikan di Indonesia masih perlu terus ditingkatkan kualitasnya termasuk meningkatkan kinerja dan profesionalitas para guru.

Banyak faktor yang dapat dijadikan alat untuk meningkatkan kualitas pendidikan. Salah satunya adalah usaha yang dilakukan Pemerintah Indonesia untuk meningkatkan kualitas, kinerja dan profesionalitas para guru, sebagai-mana yang tertuang di dalam isi UndangUndang Republik Indonesia Nomor 14 Tahun 2005 tentang Guru dan Dosen. Di dalam UU tersebut diuraikan tentang kualifikasi, kompetensi dan sertifikasi guru. ${ }^{2}$ Serta dalam al Qur'an Surat al Baqarah ayat 32 yang menguraikan tentang pentingnya peran seorang guru profesional dalam Islam sebagai berikut, Mereka menjawab: "Maha suci Engkau, tidak ada yang Kami ketahui selain dari apa yang telah Engkau ajarkan kepada kami; Sesungguhnya Engkaulah yang Maha mengetahui lagi Maha Bijaksana". (QS. Al-Baqarah : 32). ${ }^{3}$

Pemerintah Indonesia melalui UU tersebut telah mengambil kebijakan dengan memberikan Sertifikat Pendidik untuk para guru sebagai bukti formal pengakuan atas kinerja dan profesionalitas seorang guru, yang kemudian dikenal dengan sertifikasi guru / pendidik. Sertifikat tersebut wajib dimiliki oleh setiap guru setelah melalui proses panjang dan tahapan yang diatur oleh lembaga atau institusi yang memiliki kualifikasi tertentu sesuai dengan peraturan perundang-undangan.

Pemberian sertifikat tersebut memang sudah banyak berpengaruh dan mampu meningkatkan kinerja dan profesionalitas guru sejak dicanangkannya
1Rahmah Maulidia, Kontribusi Pesantren pada MDGs: penguatan edukasi isu krusial kesehatan reproduksi dan safe motherhood (Imtiyaz, 2015). h.iii.
${ }^{2}$ Undang-undang Nomor 20 Tahun 2003 tentang Sistem Pendidikan Nasional \& Undang-undang No.14 th 2005 tentang Guru \& dosen (Yogyakarta, Pustaka Pelajar, 2006).

3 al-Quran, 2: 32. 
kebijakan ini, akan tetapi belum merata. Hal ini terbukti,masih banyak guru-guru MI yang belum memenuhi standar sebagai guru profesional.

Memang bisa dimengerti pula bahwa untuk mendapatkan sertifikat pendidik tidaklah mudah, karena diperlukan persyaratan yang ketat disamping kualitas kepribadian seseorang yang mumpuni serta dana yang tidak sedikit dan penguasaan terhadap teknologi informasi. Apakah ketatnya persyaratan di atas dan sulitnya pemenuhan persyaratan itu bisa dipenuhi oleh para guru di semua MI.

Menurut keterangan dari Kepala MI Misriu Al Hasan, bahwa sertifikasi guru merupakan langkah awal menuju peningkatan mutu pembelajaran dan pendidikan di daerah-daerah pelosok seperti di Desa Kraton Kecamatan Mojo Kabupaten Kediri agar mampu bersaing dengan lembaga pendidikan lain. ${ }^{4}$

Sejak didirikan pada tahun 1954, masih sedikit Guru di lingkungan MI Misriu Al Hasan yang mendapat sertifikat pendidik yang merupakan salah satu indikator profesionalitas guru.

\section{Metode}

Penelitian ini menggunakan penelitian kualitatif, sebagai cara untuk menghasilkan data deskriptif beberapa kata tertulis atau lisan dari orang-orang atau perilaku yang diamati. ${ }^{5}$ Dalam konteks ini, peneliti melakukan penggalian informasi dari kepala madrasah dan beberapa gurunya. Selanjutnya, sebagai penguat, peneliti melakukan observasi

4 Hisom Fauzi, Wawancara, 18 Desember 2019. di MI Misriu Al Hasan. dan mencari dokumen-dokumen penting sebagai data penguat. Setelah semua terkumpul, data dianalisis dengan pendekatan guru profesional yang tertuang dalam Undang-Undang Republik Indonesia Nomor 14 Tahun 2005 tentang Guru dan Dosen.

\section{Pembahasan}

\section{Syarat dan Pola Sertifikasi}

Sertifikat pendidik merupakan salah satu indikator atau ciri seorang guru disebut sebagai guru profesional. Langkah untuk mendapatkan sertifikat pendidik sebagai bagian dari peningkatan profesionalitas guru harus dilalui dengan berbagai tahapan dan segenap persyaratan.

Demikian juga dengan guru-guru di MI Misriu Al Hasan, langkah-langkah yang telah dilalui oleh guru-guru sertifikasi di MI Misriu Al Hasan untuk mendapatkan sertifikat pendidik telah sesuai dengan mekanisme dan prosedur yang seharusnya. Hal tersebut mutlak harus dilaksanakan oleh seorang guru apabila ingin meningkatkan profesionalitas.

Syarat umum yang telah dipenuhi oleh guru-guru di MI Misriu Al Hasan untuk mendapat sertifikat pendidik diantaranya a) Memiliki kualifikasi akademik minimal sarjana (S1) atau diploma empat (D-IV) dari program studi yang terakreditasi; b) Mengajar di sekolah umum di bawah binaan Departemen Pendidikan Nasional; c) Guru PNS yang mengajar pada satuan pendidikan yang diselenggarakan oleh pemerintah daerah atau

5 Johan Setiawan dan Albi Anggito, Metodologi penelitian kualitatif (CV Jejak Publisher, 2018). h. 39.

el Bidayah: Journal of Islamic Elementary Education

Volume 2, Nomor 2, September 2020 
guru yang diperbantukan pada satuan pendidikan yang diselenggarakan oleh masyarakat; d) Guru bukan PNS yang berstatus guru tetap yayasan (GTY) atau guru yang diangkat oleh Pemerintah Daerah (Pemda) yang mengajar pada satuan pendidikan yang diselenggarakan oleh Pemda; e) Memiliki masa kerja sebagai guru minimal 5 tahun pada satu sekolah atau sekolah yang berbeda dalam yayasan yang sama; f) Memiliki nomor unik pendidik dan tenaga kependidikan (NUPTK). ${ }^{6}$

Adapun syarat dan pola yang dilalui oleh guru-guru di MI Misriu Al Hasan untuk mendapatkan sertifikat pendidik, yaitu melalui tiga pola diantaranya pola Portofolio dan pola PLPG untuk yang mengikuti sertifikasi sampai akhir tahun 2015 dan PPG untuk sertifikasi mulai tahun 2016. Ada empat guru yang telah memiliki sertifikat pendidik atau sudah sertifikasi di MI Misriu Al Hasan, satu orang guru melalui pola portofolio, dua orang guru melalui pola PLPG dan satu orang guru melalui PPG.

Bapak Hisom Fauzi telah lulus melalui pola Portofolio dan mendapatkan sertifikat pendidik mulai tahun 2009 setelah melalui dan melengkapi dokumen persyaratan sesuai dengan ketentuan perundang-undangan. Sertifikasi guru pola PF dilakukan melalui penilaian dan verifikasi terhadap kumpulan berkas yang menggambarkan kompetensi guru. Komponen penilaian portofolio mencakup 1) Kualifikasi akademik; 2) Pendidikan dan pelatihan; 3) Pengalaman mengajar; 4) Perencanaan dan pelaksanaan pembelajaran; 5) Penilaian dari atasan dan pengawas; 6) Prestasi akademik; 7) Karya pengembangan profesi; 8) Keikutsertaan dalam forum ilmiah; 9) Pengalaman organisasi di bidang kependidikan dan sosial, serta 10) Penghargaan yang relevan dengan bidang pendidikan.

Peserta Sertifikasi pola Portofolio adalah guru dan guru yang diangkat dalam jabatan pengawas satuan pendidikan yang telah memenuhi persyaratan akademik dan administrasi serta memiliki prestasi dan kesiapan diri. Sementara itu, bagi guru yang telah memenuhi persyaratan akademik dan administrasi namun tidak memiliki kesiapan diri untuk mengikuti sertifikasi melalui pola PF, diizinkan mengikuti sertifikasi pola PLPG setelah lulus Uji Kompetensi Awal (UKA). ${ }^{7}$

Sedangkan Dewi Muawanah telah lulus melalui pola PLPG dan mendapatkan sertifikat pendidik mulai tahun 2011 dan Bapak Arif Ulinuha mendapatkan sertifikat pendidik mulai tahun 2014 setelah melalui beberapa persyaratan pola PLPG diantaranya, guru yang bertugas sebagai guru kelas, guru mata pelajaran, guru bimbingan dan konseling atau konselor, serta guru yang diangkat dalam jabatan pengawas satuan pendidikan yang memilih, a) Sertifikasi pola PLPG; b) Pola PF yang berstatus tidak mencapai passing grade penilaian portofolio atau tidak lulus verifikasi portofolio (TLVPF); c) PSPL tetapi berstatus tidak memenuhi persyaratan (TMP) yang lulus UKA.

(Jakarta: Direktorat Jenderal Pendidikan Tinggi Kementerian Pendidikan dan Kebudayaan, 2012), h. 6.

el Bidayah: Journal of Islamic Elementary Education Volume 2, Nomor 2, September 2020 
Sebelum mengikuti pola PLPG, Ibu Dewi Muawanah dan Bapak Arif Ulinuha diwajibkan untuk mengikuti UKG terlebih dahulu setelah memenuhi beberapa persyaratan. UKG bertujuan untuk menilai kelayakan seorang guru untuk dapat diikutkan dalam PLPG atau Pendidikan dan Latihan Profesi Guru sebagai syarat mutlak diberikannya sertifikat pendidik.

Memasuki tahun 2016, hanya ada satu pola yang dapat diikuti oleh guru yang ingin mendapatkan sertifikat pendidik yaitu pola PPG. Hal tersebut sesuai dengan Peraturan Menteri Pendidikan dan Kebudayaan Nomor 37 Tahun 2017 tentang Sertifikasi Bagi Guru dalam Jabatan yang Diangkat sampai dengan akhir Tahun 2015.8

Ibu Nur Hidayah adalah guru yang lulus melalui pola PPG Dalam Jabatan dan mendapatkan sertifikat pendidik mulai tahun 2020 ini, beliau lulus setelah melalui beberapa persyaratan diantaranya 1) memiliki kualifikasi akademik sarjana (S-1) atau diploma empat (D-IV); 2) guru dalam jabatan atau pegawai negeri sipil yang mendapatkan tugas mengajar yang sudah diangkat sampai dengan akhir tahun 2015; 3) memiliki Nomor Unik Pendidik dan Tenaga Kependidikan (NUPTK); 4) terdaftar pada data pokok pendidikan Kementerian Pendidikan dan Kebudayaan. ${ }^{9}$

Para guru di MI Misriu Al-Hasan Kraton Mojo Kediri telah melalui berbagai tahapan dan proses sesuai ketentuan ya- ng berlaku hingga akhirnya dinyatakan lulus dan layak mendapatkan sertifikat pendidik sebagai salah satu indikator guru profesional.

\section{Sertifikasi Sebagai Strategi Me- ningkatkan Profesionalitas}

Memiliki sertifikat pendidik sebenarnya sudah bisa disebut guru professional, akan tetapi sertifikat pendidik tidak serta merta menjadi jaminan bahwa seorang guru benar-benar menjalankan tugas dan kewajibannya sesuai dengan ketentuan. Terdapat kriteria penting sebagai ciri guru professional diantaranya 1) Mampu menggunakan kemampuan bertanya, yang meliputi keterampilan bertanya dasar dan kemampuan bertanya lanjutan; 2) Mampu memberi penguatan (reinforcement), yang merupakan respon terhadap suatu prilaku yang dapat meningkatkan kemungkinan terulangnya kembali perilaku tersebut; 3) Mampu mengadakan variasi yang berupa keterampilan yang harus dikuasai guru dalam pembelajaran, untuk mengatasi kebosanan peserta didik agar selalu antusias, tekun, dan penuh partisipasi; 4) Mampu menjelaskan, yang berarti mampu mendeskripsikan secara lisan tentang sesuatu benda, keadaan, fakta dan data sesuai dengan waktu dan hukum-hukum yang berlaku. Penggunaan penjelasan dalam pembelajaran memiliki beberapa komponen diantaranya perencanaan dan penyajian; 5) Mampu mem-

9 RISTEKDIKTI, Pedoman Penyelenggaraan Program Pendidikan Profesi Guru, 1 ed. (Jakarta: Direktorat Jenderal Pembelajaran dan Kemahasiswaan Kementerian Riset, Teknologi, dan Pendidikan Tinggi, 2018), h. 22.
Tahun 2015 - Pendidikan Kewarganegaraan," diakses $14 \quad$ Juni 2020 https://ainamulyana.blogspot.com/2017/12/per mendikbud-nomor-no-37-tahun-2017.html. 
buka dan menutup pelajaran, dengan memperhatikan komponen-komponen yang terkait seperti menarik perhatian peserta didik, membangkitkan motivasi, memberi acuan dan membuat kaitan; 6) Mampu membimbing diskusi kelompok kecil, dengan memperhatikan hal-hal seperti memusatkan perhatian peserta didik pada tujuan dan topik diskusi, memperluas masalah atau urunan pendapat, menganalisis pandangan peserta didik, meningkatkan partisipasi peserta didik, menyebarkan kesempatan berpartisipasi dan menutup diskusi; 7) Mampu mengelola kelas, dengan prinsip-prinsip kehangatan dan keantusiasan, tantangan, bervariasi, luwes, penekanan pada hal-hal positif dan penanaman disiplin diri; 8) Mampu mengajar kelompok kecil dan perorangan, hal itu dapat dilakukan dengan mengembangkan keterampilan dalam pengorganisasian, membimbing dan memudahkan belajar, merencanakan penggunaan ruangan dan memberikan tugas yang jelas, menantang dan menarik. $^{10}$

Guru professional apalagi yang telah mendapat sertifikasi seharusnya memi-liki perbedaan dan kinerja yang lebih baik dari guru yang belum bersertifikasi. Demikian halnya dengan guruguru sertifikasi di MI Al Hasan, para guru sertifikasi senantiasa berupaya meningkatkan kinerja dan profesionalitas sebagai seorang tenaga pendidik yang telah memiliki sertifikat pendidik.

Agar tidak terlihat sama dengan guru yang belum bersertifikat, dan sebagai bentuk pertanggung jawaban dari sertifikat pendidik yang telah dimiliki, guru sertifikasi senantiasa berupaya untuk meningkatkan kinerja dan profesionalitas diantaranya dalam hal:

\section{a. Gaya Komunikasi}

Dalam pendidikan adalah komunikasi dalam arti kata bahwa dalam proses tersebut terlibat dua komponen yang terdiri atas manusia, yakni pengajar sebagai komunikator dan pelajar sebagai komunikan.

Pada tingkatan apa pun, proses komunikasi antara pengajar dan pelajar itu pada hakikatnya sama saja. Perbedaannya hanyalah pada jenis pesan serta kualitas yang disampaikan oleh si pengajar kepada si pelajar. Perbedaan antara komunikasi dengan pendidikan terletak pada tujuannya atau efek yang diharapkan. Ditinjau dari efek yang diharapkan itu, tujuan komunikasi sifatnya umum, sedangkan tujuan pendidikan sifatnya khusus. Kekhususan inilah yang dalam proses komunikasi melahirkan istilah-istilah khusus seperti penerangan, propaganda, indoktrinasi, agitasi, dan pendidikan. Tujuan pendidikan adalah khas atau khusus, yakni meningkatkan pengetahuan seseorang mengenai suatu hal sehingga ia menguasainya.

Sejatinya, peran guru biasanya ditunjukkan melalui proses komunikasi yang dominan (didactic communications process). Didactic Communications merupakan proses yang melibatkan guru dan siswa. Di dalam prosesnya seorang guru mendemonstrasikan gaya komunikasi secara spesifik dan sanggup menentukan

\footnotetext{
10 E. Mulsaya, Menjadi Guru Profesional (Bandung: Remaja Rosdakarya,
} 2013). h. 69. 
kemampuannya dalam konteks komunikasi. Gaya komunikasi terdiri dari karakteristik individual yang berdampak pada cara komunikasi dan hal tersebut mengacu pada cara khusus dalam menerima pesan, kualitas personal dalam menginterpretasi pesan, cara yang spesifik untuk menyampaikan respon, sifat personal yang khusus dalam menyampaikan feedback.

Menurut Urea, 2013 menyatakan bahwa terdapat tiga macam gaya komunikasi antara lain: non assertive ditandai dengan kecenderungan untuk menyembunyikan atau berdiam diri apabila terdapat suatu masalah. Hal tersebut mendorong individu untuk memilih berdiam diri dari pada memicu keramaian demi terciptanya perdamaian, assertive merupakan sebuah gaya yang ditandai dengan menyatakan opini secara langsung atau terbuka agar tujuan orang tersebut terpenuhi, agresive adalah gaya komunikasi yang ditandai dengan usaha individu untuk selalu hadir atau mendekatkan diri disetiap kesempatan.

\section{b. Kedisiplinan}

Walaupun dalam hal kedisiplinan menurut keterangan dari Kepala Madrasah terkesan masih sama dengan guru yang belum bersertifikat, guru sertifikasi di MI Misriu Al Hasan telah berupaya untuk selalu meningkatkan kedisiplinan diantaranya dengan hadir dan memulai pelajaran tepat waktu.

Perihal upaya meningkatkan kedisiplinan ini telah sesuai dengan salah satu prinsip profesionalitas guru yang tertuang dalam Undang-undang tentang guru dan dosen yaitu Memiliki komitmen untuk meningkatkan mutu pendidikan, keimanan, ketaqwaan dan akhlaq mulia dan Memiliki tanggung jawab atas pelaksanaan tugas keprofesionalan guru. ${ }^{11}$

Upaya tersebut juga telah menunjukan salah satu kriteria guru profesional yaitu mampu mengelola kelas, dengan prinsip-prinsip kehangatan dan keantusiasan, tantangan, bervariasi, luwes, penekanan pada hal-hal positif dan penanaman disiplin diri. ${ }^{12}$

Kedisiplinan guru juga merupakan salah satu dari tugas seorang guru sebagai seorang pendidik, dimana seorang guru sanggup mengarahkan dan memberikan teladan kepada anak didik agar sang anak mengikuti norma maupun aturan yang berlaku di masyarakat. ${ }^{13}$

\section{c. Persiapan Sebelum Mengajar}

Salah satu kriteria guru profesional adalah mampu membuka dan menutup pelajaran, dengan memperhatikan komponen-komponen yang terkait seperti menarik perhatian peserta didik, membangkitkan motivasi, memberi acuan dan membuat kaitan. ${ }^{14}$ hal tersebut bisa terlaksana jika seorang guru sudah mempunyai persiapan yang bagus sebelum memulai pelajaran.

Guru sertifikasi di MI Misriu Al Hasan telah melakukan hal tersebut yaitu persiapan sebelum memulai pelajaran dengan membuka kembali RPP atau catatan lain yang berhubungan dengan materi yang akan diajarkan. Upaya tersebut

11 Undang-undang Nomor 20 Tahun 2003 tentang Sistem Pendidikan Nasional \& Undangundang No.14 th 2005 tentang Guru \& dosen, h. 9.

12 E. Mulsaya, Menjadi Guru... h. 69.

13 Khusnul Wardan, Guru Sebagai Profesi

(Deepublish, 2019), h. 108.

${ }^{14}$ E. Mulsaya, Menjadi Guru... h. 69. 
sering dilakukan walaupun belum setiap hari.

Upaya yang dilakukan tersebut telah sesuai dengan salah satu sub kompetensi pedagogik seorang guru yaitu merancang pembelajaran, termasuk memahami landasan pendidikan untuk kepentingan pembelajaran yang meliputi memahami landasan pendidikan, menerapkan teori belajar dan pembelajaran, menentukan strategi pembelajaran berdasarkan karakteristik peserta didik, kompetensi yang ingin dicapai, dan materi ajar, serta menyusun rancangan pembelajaran berdasarkan strategi yang dipilih. ${ }^{15}$

\section{d. Metode Mengajar yang Digunakan}

Metode merupakan salah satu komponen penting bagi seorang guru untuk mampu menyampaikan materi pelajaran dengan efektif. Ada banyak metode yang bisa digunakan dalam menyampaikan materi pelajaran agar lebih menarik perhatian siswa/siswi.

Guru-guru di MI Misriu Al Hasan cenderung menggunakan dua metode pembelajaran, yaitu metode ceramah dan diskusi. Dalam hal penggunaan metode, walaupun dinilai paling efektif guru di MI Misriu Al Hasan masih terkesan monoton dengan hanya menggunakan dua metode tersebut. Namun demikian, para guru tidak menutup diri untuk berupaya mencoba metode lain yang sesuai dengan mata pelajaran.

Upaya yang dilakukan guru sertifikasi dalam hal penggunaan metode adalah memaksimalkan metode yang sering digunakan agar lebih efektif dalam penyampaian materi serta memanfaatkan teknologi informasi dan komunikasi untuk menunjang pembelajaran.

Langkah tersebut telah sesuai dengan kompetensi profesional yaitu menguasai materi, struktur, konsep, dan pola pikir keilmuan yang mendukung pelajaran yang diampu serta mengembangkan keprofesionalan secara berkelanjutan dengan melakukan tindakan reflektif. ${ }^{16}$ Serta sejalan dengan kompetensi profesional seorang guru yaitu memanfaatkan TIK untuk berkomunikasi dan mengembangakan diri. ${ }^{17}$

\section{e. Memberikan Problem}

Solving

\section{Kepada Siswa}

Upaya guru sertifikasi di MI Misriu Al Hasan guna meningkatkan profesionalitas yang paling terlihat efektif adalah pemberian problem solving kepada para siswa.

Guru sertifikasi melakukan pendekatan personal untuk mengetahui dan berupaya memberikan motivasi kepada para siswa. Tidak hanya kepada siswa yang bermasalah, para guru sertifikasi juga berupaya menjalin komunikasi dengan orang tua atau wali.

Seorang guru memiliki tugas dan kewajiban untuk memberikan dorongan moral maupun mental kepada anak didiknya agar sang anak didik mampu menghadapi segala jenis permasalahan yang terjadi dalam hidupnya selama mengenyam pendidikan formal maupun non formal. ${ }^{18}$
15 Jejen Musfah, Peningkatan Kompetensi Guru: Melalui Pelatihan dan Sumber Belajar Teori dan Praktik (Kencana, 2012), h. 30. 8
16 Jejen Musfah, Peningkatan... h. 32.

17 Jejen, h. 32.

18 Khusnul Wardan, Guru... h. 108.

el Bidayah: Journal of Islamic Elementary Education Volume 2, Nomor 2, September 2020 
Upaya tersebut merupakan salah satu dari kompetensi pedagogik seorang guru yaitu memahami peserta didik secara mendalam yang meliputi memahami peserta didik dengan memamfaatkan prinsip-prinsip perkembangan kognitif, prinsip-prinsip kepribadian, dan mengidentifikasi bekal ajar awal peserta didik. ${ }^{19}$

Hal tersebut juga sejalan dengan tugas guru yaitu memberi bimbingan dan arahan kepada peserta didik. Bimbingan dan arahan ini diharapkan mengembangkan kemampuan motorik maupun kemampuan lain yang dimiliki seorang anak didik. $^{20}$

\section{f. Organisasi dan Aktifitas Penunjang}

Mampu mengelola kelas dan kelompok kecil merupakan salah satu indikator guru professional yang menunjukkan seorang guru mampu mengorganisir pembelajaran. Dalam hal ini, kegiatan organisasi yang diikuti oleh guru sertifikasi diharapkan akan lebih meningkatkan profesionalitas guru dalam menjalankan kewajibannya. Karena beberapa alasan, tidak semua guru sertifikasi di MI Misriu Al Hasan mengikuti organisasi keguruan atau yang sesuai dengan profesi keguruan.

Hanya ada 2 gruru sertifikasi yang mengikuti oraganisasi profesi diantaranya Persatuan Guru Inpassing Nasional (PGIN) dan Kelompok Kerja Guru (KKG) di tingkat kecamatan. Sedangkan guru sertifikasi yang lain aktif dalam organisasi kemasyarakatan Muslimat NU.

Guna meningkatkan kualitas pembelajaran dan pengetahuan guru ser- tifikasi, para guru berupaya untuk mengikuti berbagai pelatihan dan seminar diantaranya Diklat kurikulum K-13, Diklat Kepala Madrasah dan seminar serta pelatihan-pelatihan minimal sekali dalam satu tahun.

Upaya yang telah dilakukan guru sertifikasi MI Misriu Al Hasan dalam mengikuti organisasi telah sejalan dengan prinsip profesionalitas guru yaitu memiliki organisasi profesi yang mempunyai kewenangan mengatur hal-hal yang berkaitan dengan tugas keprofesionalan gu$\mathrm{ru},{ }^{21}$ serta merupakan salah satu kriteria guru profesional yaitu mampu mengajar kelompok kecil dan perorangan, hal itu dapat dilakukan dengan mengembangkan keterampilan dalam pengorganisasian, membimbing dan memudahkan belajar, merencanakan penggunaan ruangan dan memberikan tugas yang jelas, menantang dan menarik. ${ }^{22}$

\section{Kesimpulan}

Syarat dan pola sertifikasi guru di MI Misriu Al Hasan Kraton Mojo Kediri telah dilaksanakan sesuai ketentuan yang berlaku, ada 4 (empat) orang guru yang mengikuti program sertifikasi guru tersebut.

Upaya yang dilakukan oleh guru sertifikasi di MI Misriu Al Hasan Kraton Mojo Kediri antara lain meningkatkan kedisiplinan agar lebih baik dari guru lain non sertifikasi, mempersiapkan diri dan materi sesuai dengan rencana yang telah disusun dengan sebaik-baiknya, menggunakan metode pembelajaran yang tepat dan efektif sesuai dengan kondisi siswa,

\footnotetext{
${ }^{19}$ Jejen, h. 30. Oemar Hamalik, Proses Belajar dan Dosen, h.9.

Undang-undang, Tentang Guru ${ }^{22}$ E. Mulsaya, Menjadi Guru... h. 69. 
memberikan problem solving secara personal dan intensif kepada para siswa yang bermasalah, mengikuti organisasi profesi dan organisasi kemasyarakatan untuk menunjang kinerja dalam pembelajaran, serta dengan mengikuti diklat dan seminar guna meningkatkan kemampuan dan pengetahuan dalam melaksanakan kewajiban sebagai guru professional.

\section{Daftar Pustaka}

Al-Qur'an dan Tejemahnya. Bandung: CV Diponegoro, 2011.

Anwar, Muhamad. Menjadi Guru Profesional. Prenada Media, 2018.

BUKU 2 / Petunjuk Teknis Pelaksanaan Sertifikasi Guru di Rayon LPTK. Jakarta: Direktorat Jenderal Pendidikan T inggi kementerian Pendidikan Dan Kebudayaan, 2012.

Jejen Musfah. Peningkatan Kompetensi Guru: Melalui Pelatihan dan Sumber Belajar Teori dan Praktik. Kencana, 2012.

Maulidia, Rahmah. Kontribusi Pesantren pada MDGs: penguatan edukasi isu krusial kesehatan reproduksi dan safe motherhood. IMTIYAZ, 2015.

"Permendikbud Nomor 37 Tahun 2017 Tentang Sertifikasi Bagi Guru Dalam Jabatan Yang Diangkat Sampai_Dengan Akhir Tahun 2015 - Pendidikan Kewarganegaraan." Diakses $14 \quad$ Juni 2020. https://ainamulyana.blogspot.com /2017/12/permendikbud-nomorno-37-tahun-2017.html.

Ristekdikti. Pedoman Penyelenggaraan Program Pendidikan Profesi Guru.
1 ed. Jakarta: Direktorat_Jenderal Pembelajaran dan Kemahasiswaan Kementerian Riset, Teknologi, dan Pendidikan Tinggi, 2018.

Setiawan, Johan, dan Albi Anggito. Metodologi penelitian kualitatif. CV Jejak Publisher, 2018.

Sukmadinata, Metode penelitian pendidikan. Bandung: Program Pascasarjana Universitas Pendidikan Indonesia dengan PT Remaja Rosdakarya, 2005.

Undang-undang Nomor 20 Tahun 2003 tentang Sistem Pendidikan Nasional \& Undang-undang No.14 th 2005 tentang Guru \& dosen. VisiMedia, t.t.

Wardan, Khusnul. Guru Sebagai Profesi. Deepublish, 2019. 